\title{
EDITORIAL
}

\section{The future of lung research in the UK}

\section{Stephen T Holgate}

Thorax 2007;62:1028-1032. doi: 10.1136/thx.2007.088971

$\mathrm{T}$ he 25th anniversary of the British Thoracic Society (BTS) and the 60th anniversary of the Society's journal, Thorax, seems an appropriate time to take stock of where we have come from, where we are now and where we wish to be in the future. Our beginning had its roots in the industrial revolution with poor and overcrowded housing and the ever present scourge of tuberculosis (TB). It was in 1928 that an ENT surgeon, St Clair Thomson, brought together The Sanatorium Superintendents' Society, The Tuberculosis Society and The Nursing Committee into a single professional body, The Tuberculosis Association, which was reformed in 1945 as The British Tuberculosis Association (BTA), interested in the prevention and treatment of tuberculosis (fig 1). ${ }^{1}$ The Association was small but highly effective in driving forward new ways of managing TB centred on sanatoria, fresh air and good food, but was quite separate from main stream medicine and surgery. With the incorporation of the Joint Tuberculosis Council, a second powerful group with responsibility for maintaining standards in $\mathrm{TB}$ care, and the increasing recognition that the health impacts of lung disease extended far wider than TB, the British Thoracic and Tuberculosis Society emerged in 1968. It was decided to simplify its name in 1977 to the British Thoracic Association. The final iteration occurred in 1982 when, after some deliberation, the more academic Thoracic Society (that had its origins largely in academic physiologists and a forum for presenting research) merged with the BTA to accommodate the changing face of lung disease. ${ }^{2}$ The new British Thoracic Society (BTS) met the principles laid out by Sir William Osler who stated that "the attributes of a good professional society should be to help members discover their true professional potential and keep them receptive and abreast of advances in their subject" ${ }^{\prime \prime}{ }^{13}$

While maintaining high clinical standards and providing educational and postgraduate training opportunities, research should lie at the heart of any medical speciality. Research reflects the scintillating edge where new science is presented for translation into practice, while also providing opportunities for professionals to contribute to the growth and improvement of their speciality and, in doing so, enrich their own experience. This, of course, is not new. Records from the minutes of the BTA in 1958 revealed the steady fall in deaths from TB from 1928 onwards, in large part due to improved housing, social conditions and nutrition as well as earlier diagnosis and the impact of the sanatoria treatment regimes that included various forms of lung collapse surgery driven in large part by the BTA and the Joint Tuberculosis Council. ${ }^{45}$
However, what was so dramatic was the halving of deaths in the 6 years from 1948 to 1956 when streptomycin was first introduced. The excitement of this new treatment was captured at the BTA Oxford meeting in 1946 when the guest speaker Dr W H Feldman of the Mayo Clinic described the use of streptomycin in experimental TB in guinea pigs. Despite this major breakthrough, he stated that streptomycin was difficult to prepare and he considered that it would be some time before sufficient drug was available for large-scale use in humans. ${ }^{67}$ It was an epoch-making paper and, many years afterwards, the then President, Dr Norman Tattersall, who was in the chair at the Oxford meeting considered it to be "the most exciting moment in his professional life". ${ }^{1}$ In September 1946 Dr Honor Smith described the successful use of streptomycin for the treatment of tuberculous meningitis in a patient and this was probably the first scientific description of its clinical use in Britain. ${ }^{8-10}$

\section{EARLY YEARS OF MEDICAL RESEARCH AND THE MRC}

Following a Royal Commission enquiry in response to the rising TB epidemic at the start of the 19th century, the then prime minister Lloyd George asked a young surgeon Christopher Addison (previously professor of surgery at Sheffield and of Addison's plane fame) to help establish the first government-funded Medical Research Committee on 20 June 1913 under the chairmanship of Lord Moulton. The purpose of this "MRC" was to oversee better research into the causes and management of human disease, especially TB. ${ }^{11}{ }^{12}$ In 1920 The Medical Research Council (MRC) emerged by Royal Charter with the "responsibility for the adequacy of the national effort in medical research" ${ }^{12}$ To this day the MRC represents the UK government's support for medical research across the full spectrum of biological, physical and social sciences.

The current mission of the MRC is Discovery Science for Health. This includes encouraging and supporting high quality research with the aim of maintaining and improving human health, producing skilled researchers, advancing and disseminating knowledge and technology to improve the quality of life and economic competitiveness in the

Abbreviations: AMS, Academy of Medical Sciences; BLF, British Lung Foundation; BTA, British Tuberculosis Association; BTS, British Thoracic Society; COPD, chronic obstructive pulmonary disease; MRC, Medical Research Council; OSCHR, Office for Strategic Coordination of Health Research; TB, tuberculosis; UKCRC, UK Clinical Research Collaboration; UKCRN, UK Clinical Research Network; UKRRC, UK Respiratory Research Collaborative
Received 16 August 2007 Accepted 27 August 2007 


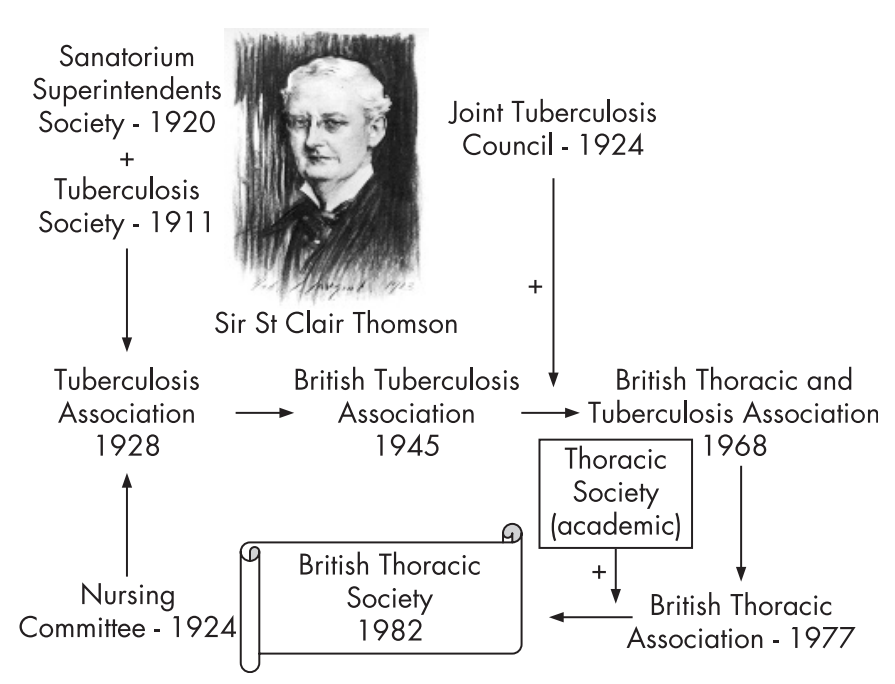

Figure 1 The evolution of the British Thoracic Society.

UK and to promote dialogue with the public about medical research. Its annual budget in 2006/7 was £575 million across six Research Boards which have delegated responsibility for funding research grants, units, centres and training awards equally between the intramural and extramural programmes. Today the MRC's research effort is at least equalled by the medical research charities and-as will become apparent-a large increase in support from the Department of Health (DH). Despite achieving considerable success since its inception, advances in science and technology together with an unprecedented need for evidence to inform diagnosis and treatment, the MRC and the other research funding bodies are in the process of evolving to meet the ever-increasing demands placed upon them.

\section{THE NHS RESEARCH AND DEVELOPMENT PROGRAMME}

In 1988 the House of Lords Select Committee on Science and Technology completed an enquiry identifying an urgent need for the NHS itself to have a research function outside policy support and to bring new approaches to health care. ${ }^{13}$ The NHS Research and Development (R\&D) Programme, led by Sir Michael Peckham, was launched in 1990 and soon established a series of regional $R \& D$ centres that held their own budgets to implement a research culture across the full range of NHS activity, but with a special focus on clinical trials, health service research and improved service development. ${ }^{14}$ However, despite a promise for scaled-up funding, this enterprise was restrained with most NHS R\&D money being locked into NHS hospitals as the Service Increment for Teaching and Research (SIFTR). However, despite numerous attempts to liberate and then protect R\&D funding from being used to support health service costs (including those of the Culyer Report of $1994^{15}{ }^{16}$ ), this proved to be an impossible task.

\section{A CHANGE OF HEART AND DIRECTION}

Since the millennium, a series of highly influential reports have been published that have had a profound effect in helping to reshape the medical research landscape:

- The Pharmaceuticals Industries Competitiveness Task Force (PICTF) report Competitiveness and Performance Indicators 2005; ${ }^{17}$

- The Biosciences Innovations and Growth Team (BIGT) report (2003) Biosciences 2015:18

- The Academy of Medical Sciences (AMS) report (2002) Clinical Academic Medicine in Jeopardy: Recommendations for Change; ${ }^{19}$
- The Academy of Medical Sciences UK Evaluation Forum report (2003) Medical Research: Assessing the Benefits to Society; ${ }^{20}$ and, most recently,

- The Sir David Cooksey report (2006) A Review of UK Health Research Funding. ${ }^{21}$

These enquiries have all highlighted major concerns about the state of clinical and biomedical research in the UK with an urgent need for change. They have helped stimulate establishment of a high level DH Research for Patients Benefit Working Party $^{22}$ which has arrived at far-reaching conclusions to radically overhaul health-related $\mathrm{R} \& \mathrm{D}$ activity including capacity building for clinical science and translational medicine.

Based on a forward looking R\&D Strategy, Best Research for Best Health, a National Health Research Strategy (January 2005), Dr Sally Davies (Director General of R\&D at the DH and NHS) announced that the $£ 550$ million embedded in the NHS trusts was to be released and reinvested transparently in patient-based translational medicine, clinical trials and health research. ${ }^{23}$ Next year the budget will be $£ 776$ million. A component of the new R\&D infrastructure has been the establishment of the National Institute for Health Research and the UK Clinical Research Network (UKCRN, www.ukcrn.org.uk). Building on an already successful model used by Cancer Research UK, Clinical Research Networks have been created in priority areas: Medicines for Children (MCRN), Diabetes (DRN), Dementias and Neurodegenerative Disease (DeNDRoN), Stroke (SRN), Cancer (NCRN) and Mental Health (MHRN). During 2007-8 the UKCRN is being expanded to cover the full spectrum of disease by creating the Comprehensive Local Clinical Research Network (CLRN) comprising 25 units within Strategic Health Authority boundaries across England. The purpose of the CLRN is: (1) to provide the NHS infrastructure to support clinical research using local capacity and expertise; (2) to fund NHS support costs with flexible per capita support; and (3) to help streamline and deliver research management but not to develop the research portfolio; this is the responsibility of the research community. Links are also being made to related developments in Scotland, Wales and Northern Ireland with the aim of providing a world class health service infrastructure to support clinical research. The disease-specific and the CLRNs will take on studies funded by a UK Clinical Research Collaboration (UKCRC) partner who awards in national open competition and commercial studies and trials after adoption.

\section{ADDRESSING RESEARCH AND DEVELOPMENT GAPS}

In December 2006 the Cooksey Report ${ }^{21}$ raised important concerns regarding the harnessing of UK medical research into patient and commercial benefit ("development gaps"). The report identified two major barriers to research translation: taking forward basic science discoveries into practical developments and trialling developments on patient pathways and implementing these as part of evidence-based health care (fig 2). To address these, a new overarching Office for Strategic Coordination of Health Research (OSCHR) was proposed, charged with the task of bringing together a seamless model of research from discovery to development and implementation involving both the DH and NHS R\&D programme through its National Institute for Health Research and the MRC. OSCHR will establish and oversee the activities of three new research boards: Translational Medicine, Public Health and " $\mathrm{e}$ " Health (research use of databases such as the NHS Connecting for Health network) (fig 3).

\section{IMPLICATIONS FOR LUNG RESEARCH}

Historically the UK has pioneered lung research, starting with $\mathrm{TB}$ and then taking on the challenges of industrial lung disease 


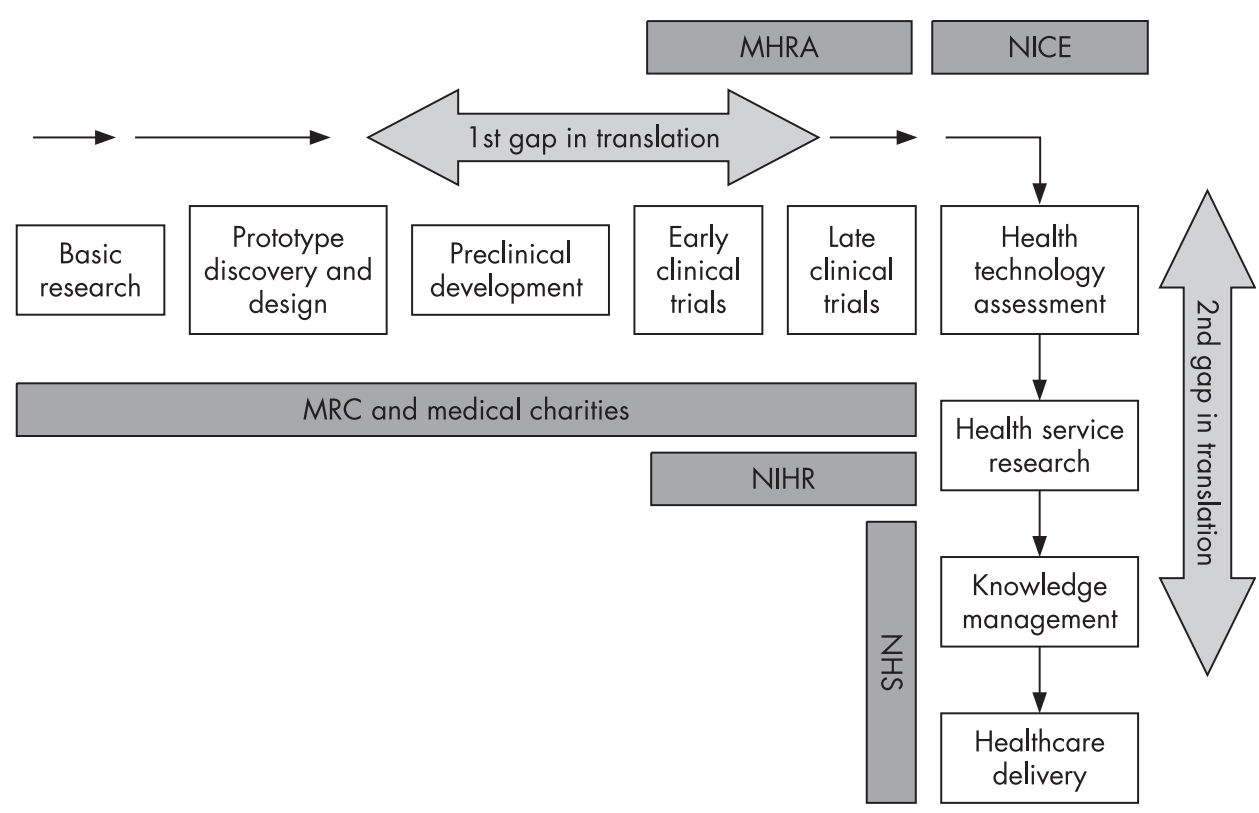

Figure 2 Pathway for translation of health research into healthcare improvement as referred to in the Cooksey Report of 2006. MHRA, Medicines and Healthcare Products Regulatory Agency; NICE, National Institute for Health and Clinical Excellence; MRC, Medical Research Council; NIHR National Institute for Health Research; NHS, National Health Service.

associated with mining and other dust-related activities, tobacco smoking, air pollution, asthma and, most recently, chronic obstructive pulmonary disease (COPD). However, recent evidence gathered by the UK Clinical Research Collaboration (UKCRC) indicates that, among 20 organ-based fields of research, lung disease has the greatest disparity between disease burden and research activity in the UK (fig 4A). ${ }^{24}$ A separate survey conducted by the BTS has also revealed that academic research in lung disease is decreasing rapidly with few trainees wishing to follow this career path, an observation that accords with the AMS report on the state of clinical academic medicine. ${ }^{19}$ A detailed examination of the type of research which conventionally receives support from the MRC, DH and the medical research charities indicates a heavy bias towards aetiological and pathophysiological studies with relatively little evidence of translation to patient benefit (fig 4B). It is important to note, however, that this analysis does not include research funded by industry.

At a time when respiratory diseases such as asthma and associated allergy, COPD, cancer and interstitial lung disease are reaching an all-time high and diseases that were thought to

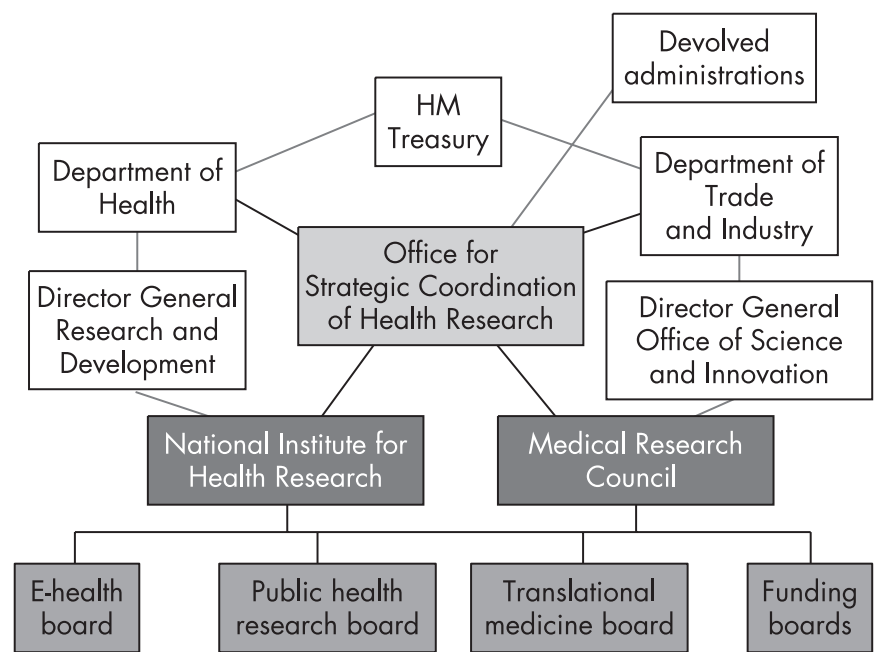

Figure 3 A single integrated strategy for medical research in the UK as proposed in the Cooksey Report, 2006. be under control such as TB and bacterial pneumonias are reemerging with antimicrobial resistance, the time has come for action. The climate in the UK is now ready to accommodate a major push from the lung research community for a large increase in activity across the full spectrum of respiratory research. In October 2005 a meeting of research funders (DH, MRC, Wellcome Trust, Asthma UK, the British Lung Foundation (BLF)) and researchers at the Royal College of Physicians (RCP) identified the fragmented nature of lung research in the $\mathrm{UK}^{25}$ and, as pointed out by Geoffrey Laurent in a previous editorial in Thorax, ${ }^{26}$ an overcautious and competitive climate that was damaging rather than enhancing lung research. Collaboration and clinical trial activity was poorly developed and, in some areas such as lung cancer, was almost absent when compared with activity in related areas such as breast, bowel, skin and prostate cancer. As identified in the Cooksey Report, ${ }^{21}$ there were also difficulties in drawing discoveries in cancer into clinical benefits. ${ }^{27}$ How do we make inroads to redress the balance between disease burden and research? What is the best model to capitalise on new discoveries and move these across to benefit patients? What emerged from the RCP meeting was an urgent need for a much more joined-up and integrated approach to lung disease research that cut across institutional and professional barriers, was inclusive and multidisciplinary.

\section{A new beginning: the UK Respiratory Research Collaborative}

Rapidly, these concerns led to the establishment of the UK Respiratory Research Strategy Committee (later renamed the UK Respiratory Research Collaborative, UKRRC) with the objective of bringing together the principal funders of lung research with all of the lung-related professions, their societies and researchers themselves in an attempt to rebuild lung research in the UK. ${ }^{25}$ The aims of the UKRRC are to:

- produce and update a strategy for respiratory research in consultation with constituent groups and others;

- promote the need for world class research into respiratory disease;

- facilitate translational research in respiratory medicine;

- continue working to raise the profile of respiratory research in the UK; 

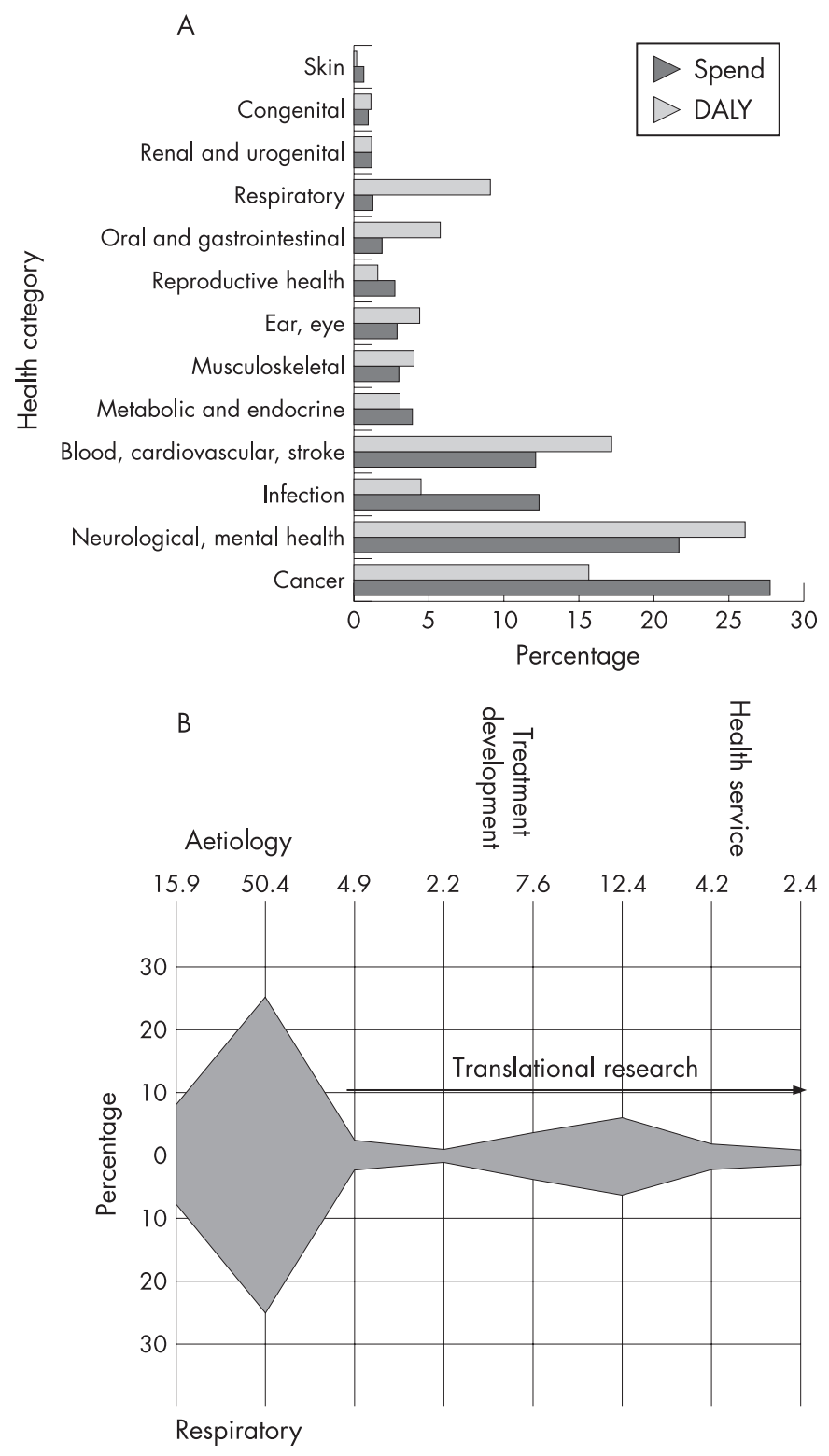

Figure 4 (A) Estimated total research spend by the Research Councils and medical charities in relation to disease burden expressed as disabilityadjusted life years (DALYs) for the UK in 2002 for a range of health categories. Note the low research spend in relation to the high disease burden for lung diseases. (B) Proportion of research spend in respiratory disease according to research type. Data from UKCRC. ${ }^{24}$

- raise awareness of the need for a good career structure for respiratory researchers;

- promote conditions in which more research can take place in NHS settings;

- work to increase the funding for respiratory research in the $\mathrm{UK}$;

- raise awareness of the amount that has been achieved by the respiratory research community;

- liaise with UK agencies and research funders to share information;

- respond to consultations where a united response would be helpful; and

- work jointly towards a shared aim of improved disease prevention and patient care.
A first step for the new UKRRC was to generate a list of priority areas for research recognising that, to be effective, a focus based on unmet clinical need was required. Themes that emerged from this consultation process were: early life events development and lung aging, airways diseases and sleep apnoea syndromes, respiratory infections, lung cancer, mechanisms of lung injury, repair and regeneration, phenotyping respiratory diseases and delivery of care for lung disease. ${ }^{25}$ The UKRRC considers good communication to be critical and has formed a small subgroup to oversee this. One output has been a regular newsletter widely distributed for display through members' websites; four newsletters have so far been published and can be accessed easily via the UKRRC on the BTS website (www.brit-thoracic.org.uk). In parallel, the MRC's Physiological Systems and Clinical Sciences Board, through their Strategic Portfolio Oversight Group, recognised the parlous state of UK lung research and issued a Highlight Notice drawing attention to the problem and requesting the research community to respond. This has already resulted in a large increase in grant submissions and the proportion that have been successfully funded. An early success of the UKRRC was an agreement with the MRC Training Board-in collaboration with the BLF, the BTS with the Morrison Scadding Trust and Asthma UK-to fund 21 new PhD studentships dedicated to lung research for 2007/8. The Heart Chest and Stroke Association of Northern Ireland have also agreed to sponsor two new studentships jointly with the NHS. This has been followed by agreement to create three new Clinical Training Fellowships for 2007/8 jointly funded by the MRC, BLF, Asthma UK and the CF Trust.

\section{An urgent need for more well-designed clinical trials in lung disease}

Lack of high quality clinical trials, especially in chronic conditions, involving non-drug as well as pharmaceutical and biological interventions, is also a great concern. To address this, the UKRRC has asked each of the major lung research charities, along with other groups within the UKRRC who have already carried out or are in the process of carrying out prioritisation of topics where there is a perceived and easily identifiable clinical need for trials, to generate a long list of research questions in urgent need of addressing. Asthma UK had already completed an update of their extensive survey of research needs in Basic Asthma Research (BARS 2) and is soon to complete a similar exercise in Clinical Research (CARS). The BLF had also asked its Research Committee to draw up a list of priority themes, especially in the area of chronic lung disease. The lists of trials that the UKRRC will initially be prioritising will be in asthma, COPD, non-asthma paediatric lung disease, interstitial pulmonary fibrosis and lung cancer. Within each area a short list of 2-3 highest priority research questions will be identified using the Delphi method and these will be taken forward by research leaders as national clinical trials. This will require champions in each of the selected areas to form a clinical trial subgroup in order to work up a grant proposal for submission to a national funding body. The trials will aim to address tractable questions, be amenable to multicentre study and, where appropriate, be multidisciplinary. Success will be the funding of several of these to be rolled out within the CLRN. Clearly, the six topics chosen for this first exercise is only a start from which we will undoubtedly learn, and it is the intention of the UKRRC to repeat several cycles of prioritisation in order to cover the full spectrum of lung disease.

Future activities of the UKRRC will include discussions with Cancer Research UK over the possibility of capacity building fellowships in lung cancer and engagement with the pharmaceutical, biotechnology and diagnostics industries over joint initiatives to strengthen respiratory research. This latter activity 
is not only important in further developing joint research proposals and trials, but also to increase the capacity of lungbased science in the fields of pharmacology, physiology and toxicology fundamental to the development of a successful industrial and clinical research base. ${ }^{17}{ }^{18}$

\section{A shortfall of researchers}

People are key to delivering research. ${ }^{23}$ The fall-off in young basic and clinical scientists wishing to pursue an academic and research career in the UK is therefore a real concern. ${ }^{19}{ }^{23}$ Capacity building, including new clinical and non-clinical studentships, fellowships and career development awards, needs to take place in all areas of respiratory health and to positively include primary care physicians, pharmacists, allied health professionals and nurses. Academic champions are needed to encourage and nurture promising research talent as proposed by the AMS report. ${ }^{19}$ There also needs to be greater opportunity to enable those wishing to change career direction to incorporate some research activity or, in some cases, to making research a full-time career. The various groups that represent the professions could greatly facilitate the UKRRC aims by coming together under "A Big Tent" concept to share expertise, support and resources and to establish new ways of working that can be generalised across the country. This will require generosity of spirit and a true sense of multidisciplinarity, collegiality and collaboration. One good way to start this process would be to provide a forum for all young researchers to meet on a regular basis to present and discuss their work and career paths with senior colleagues and to receive dedicated support to facilitate their training. Such a group needs to be valued and nurtured since they will be the academic leaders of the future.

\section{CONCLUDING COMMENTS}

Maybe the 25th anniversary is a time to see what can be achieved by pulling together towards common objectives. As stated at the start of this review, research in lung disease must reflect the glittering edge of our speciality and, in doing so, it will be addressing the most important unmet clinical needs of our patients. In addition, as stated by Norman Tattersall in 1946, research should represent "the most exciting moments in our careers". What better way to start the next 25 years of the BTS.

\section{ACKNOWLEDGEMENTS}

The author wishes to acknowledge the help of Sheila Edwards and Angela Hurlstone at the BTS, Rachel Garrod, Co-Chair, and members of the UKRRC.

Competing interests: None.
The subject matter of this review was presented at the 2007 Summer Meeting of the BTS in Manchester.

\section{REFERENCES}

1 Snell WE. The British Thoracic Association: the first fifty years. London: British Thoracic Association, 1978.

2 Milne L. The British Thoracic Association. 50th anniversary meeting held at Bournemouth, 19-22 April 1978. Abstracts of papers presented. Br J Dis Chest 1978:72:253-62.

3 Turner-Warwick M. The British Thoracic Society. Thorax 1982;37:321-3.

4 Vynnycky E, Fine PE. Interpreting the decline in tuberculosis: the role of secular trends in effective contact. Int J Epidemiol 1999:28:327-34.

5 Davies RP, Tocque K, Bellis MA, et al. Historical declines in tuberculosis in England and Wales: improving social conditions or natural selection? Int J Tuberc Lung Dis 1999;3:1051-4.

6 Karlson AG, Feldman WH. The use of guinea pigs in studying chemotherapy of experimental tuberculosis. Ann NY Acad Sci 1949:52:637-45.

7 Karlson AG, Gainer JH, Feldman WH. The effect of dihydrostreptomycin paraaminosalicylate on experimental tuberculosis in guinea pigs. Am Rev Tuberc 1950;62:149-55.

8 Smith HV, Vollum RL. Effects of intrathecal tuberculin and streptomycin in tuberculous meningitis: an interim report. Lancet 1950;2:275-86.

9 Pfuetze KH, Pyle MM, Hinshaw HC, et al. The first clinical trial of streptomycin in human tuberculosis. Am Rev Tuberc 1955:71:752-4.

10 Feldman WH. Streptomycin: some historical aspects of its development as a chemotherapeutic agent in tuberculosis. Am Rev Tuberc 1954;89:859-68.

11 Bryder L. Tuberculosis and the Medical Research Council, 1911-1939. Soc Soc Hist Med Bull (Lond) 1985;37:68-71.

12 Thomson L. Origin and development of the Medical Research Council. BMJ 1963:2:1290-2.

13 House of Lords Select Committee on Science and Technology. Priorities in medical research. London: HMSO, 1988

14 Woods KL. NHS R\&D achievements and future challenges. J Clin Pharmacol 2003:55:477-9.

15 Culyer AJ. The Culyer Report. Lancet 1994;344:1774.

16 Culyer AJ. Supporting research and development in the National Health Service. Report of a meeting of the 1942 Club, January 1995. The recommendations. J R Coll Physicians Lond 1995;29:216-24.

17 Pharmaceutical Industry Competitiveness Task Force (PICTF). Competitiveness and performance indicators. London: Department of Health and Association of British Pharmaceutical Industries, 2005

18 Biosciences Innovations and Growth Team/Biolndustry Association. Biosciences 2015. London: M2 Presswire, 2003.

19 Academy of Medical Sciences (AMS). Clinical academic medicine in jeopardy: recommendations for change. London: AMS Publications, 2002

20 Academy of Medical Sciences (AMS) UK Evaluation Forum. Medical research: assessing the benefits to society. London: AMS Publications, 2003

21 Cooksey D. A review of UK health research funding. A report for HM Treasury. London: HMSO, 2006.

22 Department of Health. Research for Patients Benefit Working Party, Final Report. London: HMSO, 2006.

23 Davies S. New structures for health research support. J Foundation Sci Technol 2007; 19:6-7.

24 UK Clinical Research Collaboration (UKCRC). UK health research analysis. London: UKCRC, 2006.

25 Holgate ST. Priorities for respiratory research in the UK. Thorax 2007;62:5-7.

26 Laurent GJ. Getting grant applications funded: lessons from the past and advice for the future. Thorax 2004:59:1010-1.

27 Kargul J, Laurent GJ. Cancer research: translating scientific advances into taming the global disease. Int J Biochem Cell Biol 2007;39:1277.

No busy professional has time to browse through all pertinent journals to find relevant articles, but with Related Collections you no longer have to. Follow the "Related Collections" link from any article and use the "Show Collections from other Journals" to expand your search across all BMJ Journals. Or simply follow the "Browse by topic" link on the home page. By setting up your own collections and receiving email alerts every time an article is added to your chosen area, you can build up your own significant body of knowledge. 